\title{
Online resources on writing, publishing, and presenting: some top choices for the medical community
}

(Index words: publication, journals, presentations, websites)

Ceylon Medical Journal 2016; 61: 96-98～～DOI: http://doi.org/10.4038/cmj.v61i3.8343

\section{Introduction}

The Sri Lankan medical community has become increasingly active and visible in research communication. For example, according to Ranasinghe et al, the number of Scopus-indexed medical publications by Sri Lankan authors grew on average 9.1\% per year from 2000 to 2009 [1]. Similarly, the yearly numbers of PubMedindexed articles listing an author with Sri Lankan affiliation have increased greatly in recent decades. Yet, the output of medical research publications from Sri Lanka remains relatively small [1]. To help address this situation, these authors have called for 'an enabling environment for research', including suitable training. Such training, it may well be argued, should include instruction not only on how to do research but also on how to communicate it.

In the last several years, instructions on communicating medical and other research has become increasingly available in Sri Lanka. For example, the Sri Lanka Medical Association has held many workshops and presentations wholly or in part on writing and publication. The University of Colombo, Faculty of Medicine has established a Research Promotion and Facilitation Centre [2], the activities of which include writing workshops and writing clubs. Since 2010, Author AID, a project of the international development charity INASP, has held and funded workshops in Sri Lanka on research writing, the teaching of research communication, and research-writing mentorship.

Such activities, however, do not fully meet the needs of the Sri Lankan medical community for information on writing, publishing, and presenting. For example, a workshop may not be available when an author is seeking guidance, may not be feasible to attend, or may not provide the specific information sought. Fortunately, many online resources helpful in medical writing, publishing, and presenting are now available. This article will identify and discuss some of the most useful of these resources. It will first focus on a 'meta-resource' encompassing multiple resources on the subject. Then it will identify resources for writing and publishing journal articles. Finally it will present resources on some other aspects of medical and scientific communication.

\section{AMeta-Resource:AuthorAID}

The website of AuthorAID, a project mainly to help researchers in developing countries to write about and publish their work, is a gateway to a variety of resources [3-5]. Perhaps most notably, the website includes a resource library with more than 700 resources, both from AuthorAID itself and from many other sources [6]. The resource library contains presentations, articles, videos, and more. Among topics of the resources are writing scientific papers, review articles, case reports, and grant proposals; preparing oral presentations, poster presentations, and grant proposals; and English-language writing style.

The AuthorAID website includes a blog (labelled 'News') on research communication and related topics. To receive email alerts when new blog posts or resources become available, one can register on the blog's homepage (http://www.authoraid.info/en/news/). One can also seek and offer mentorship through the AuthorAID website. In addition, AuthorAID has an email discussion list, in which participants can pose questions about research communication; to join the list, see https://dgroups.org/ groups/authoraiddiscussion

Since 2011, Author AID has offered online courses, derived from face-to-face AuthorAID workshops. Initially these online courses were limited to relatively small groups, but recently they have included massive open online courses (MOOCs), with hundreds of registrants. Although these MOOCs are synchronous and so can be taken only during certain ranges of dates, participants can choose when each week to do the work. Thus, these courses can suit busy medical professionals well. For announcements of upcoming AuthorAID MOOCs, please watch the AuthorAID website and discussion list.

\section{Some resources on writing and publishing}

For authors writing research articles for journals, valuable resources include the Clinical Chemistry Guide to Scientific Writing, a series of 14 articles [7]. This series includes articles on preparing the various parts of a

This is an open-access article distributed under the terms of the Creative Commons Attribution License, which permits unrestricted use, distribution, and reproduction in any medium, provided the original author and source are credited. 
scientific paper, on designing figures and tables, on writing review articles, and on responding to comments from reviewers and editors. Taken together, these articles can serve almost as a textbook.

The AuthorAID resource library contains many presentations on writing and publishing journal articles [6]. Recent additions include the core slides from a 3-week intensive course in research writing [8]. For those wanting a rapid overview on the subject, the presentation Writing and Publishing Journal Articles: Ways to Decrease Stress and Increase Success, given for the Sri Lanka Medical Association,offers key tips [9].

Although content and organization are primary, use of language also is important. A language resource worth bookmarking is OneLook Dictionary Search [10]. Users of this resource can look up words simultaneously in multiple dictionaries, including medical dictionaries. Some of the dictionaries contain audio links to pronunciations - a particular advantage if one is presenting orally. Another helpful language resource is Academic Phrasebank [11]. This resource contains lists of phrases useful in specific parts of journal articles. Browsing through the phrases, which are grouped by function, can aid in finding suitable wording. Because the phrases are brief and common, using them does not constitute plagiarism.

Journals' instructions to authors provide directions on preparing papers appropriately for specific journals; some also provide general guidance on medical writing or are accompanied by resources supplying such guidance. Yet many authors seem to neglect these instructions. Journals' instructions (which sometimes have other names, such as 'author guidelines') normally appear on the journals' websites. Also, the website Instructions to Authors in the Health Sciences provides links to instruction-containing websites for more than 6000 journals [12]. This website also has links to some guidelines for types of medical papers.

Among guidelines that clinicians might find especially helpful are the CARE guidelines for writing case reports [13]. These guidelines and many other guidelines - for example, for reporting randomised trials, observational studies, and systematic reviews - can be accessed through the website of the EQUATOR (Enhancing the QUAlity and Transparency Of health Research) Network [14].

As well as following the journal's instructions, authors should access some articles of the same type in the journal and use them as models. Such models can be a valuable resource. Before writing the current article, I read the Ceylon Medical Journal author guidelines and looked at some recent leading articles in the journal. The author guidelines indicated how long the article should be and how many references to include. However, only by looking at the recent leading articles did I know whether to include subheadings.
Good writing commonly is much-revised writing. Yet most medical authors lack the luxury of having professional editors help them revise their work before submission. With care, however, one can edit and proof read one's writing effectively oneself. A recent article offers guidance in this regard [15]. This article contains checklists, including a general checklist, a checklist for scientific papers, and a checklist for grant proposals.

\section{Some other resources}

Giving a presentation can be an excellent step towards publication, for it entails compiling one's data and gathering one's thoughts. Also, feedback on a presentation can aid in shaping an article. A quick-reading set of slides in the Author AID resource library can help in avoiding common problems in oral and poster presentations [16]. Other materials in or linked to the resource library provide more-detailed guidance in this realm. In particular, the website Designing Conference Posters provides extensive advice and includes free templates for poster design [17].

In research and publication as in medicine, ethical conduct is crucial. High-quality resources on research ethics, including publication ethics, include two openly accessible books. One is On Being a Scientist: A Guide to Responsible Conduct in Research, from the US National Academies [18]. The other is Doing Global Science: A Guide to Responsible Conduct in the Global Research Enterprise, from the InterAcademy Partnership (a recently established organization spanning academies of science, medicine, and engineering from many countries) [19]. Each of these books is short and readable and includes cases or scenarios to consider.

Speaking of ethics: In choosing a journal for manuscript submission, it is important to ensure that the journal is a valid one, with ethical practices. Recently, some dishonest entities have started 'journals' that charge authors publication fees but do not fulfil the promised functions of peer review, editing, and publication. One resource for helping to ensure that one is submitting to a trustworthy journal is called 'Think. Check. Submit' [20]. Also, using the term 'predatory journals' to search the AuthorAID website leads to resources in this regard [3].

\section{Closing comment}

Many fine resources on medical and scientific writing, publishing, and presenting are now available online. Thus, lack of information on these subjects should no longer be a major barrier. Indeed, the growing abundance of such resources can pose challenges in deciding among them. I hope that by identifying some of the highest-yield resources on these topics, this article can help the Sri Lankan medical community to continue increasing the number and prominence of its publications. 


\section{Acknowledgements}

Some information for this article was gathered with support of INASP, through the AuthorAID project.

\section{Conflicts of interests}

The author is a consultant to the INASP project AuthorAID.

\section{References}

1. Ranasinghe P, Jayawardena R, Katulanda P. Sri Lanka in global medical research: a scientific analysis of the Sri Lankan research output during 2000-2009. BMC Res Notes 2012; 5: 121.

2. Research Promotion and Facilitation Centre, Faculty of Medicine, University of Colombo. http://www.med. cmb.ac.lk/index.php/2012-05-16-05-25-21/rpfc-menu (accessed on Aug 19, 2016).

3. AuthorAID. http://www.authoraid.info/en/ (accessed on Aug 18, 2016)

4. Gastel B. Author AID: an international service and chance to serve. Med Writing 2013; 22: 284-7.

5. Gastel B. Author AID and editors: collaborating to assist authors in developing countries. Sci Editor 2015; 38: 103-5.

6. Resources. (Author AID resource library.) http://www. authoraid.info/en/resources/ (accessed Aug 19, 2016).

7. Clinical Chemistry Guide to Scientific Writing. American Association for Clinical Chemistry. 2009-2011. https:// www.aacc.org/publications/clinical-chemistry/clinicalchemistry\%c2\%a0guide-to-scientific-writing (accessed on Aug 18, 2016).

8. 2016 intensive course in research writing. 2016. http:// www.authoraid.info/en/resources/details/1299/ (accessed on Aug 18, 2016).

9. Gastel B. Writing and publishing journal articles: ways to decrease stress and increase success. 2015. http://www. authoraid.info/en/resources/details/1304/ (accessed on Aug 18, 2016).
10. OneLook Dictionary Search. http://www.onelook.com/ (accessed on Aug 18, 2016).

11. Morley J. Academic Phrasebank. http://www.phrasebank. manchester.ac.uk/ (accessed on Aug 18, 2016).

12. Instructions to Authors in the Health Sciences. Mulford Health Science Library, University of Toledo. http:// mulford.utoledo.edu/instr/ (accessed on Aug 18, 2016).

13. The CARE guidelines: consensus-based clinical case reporting guideline development. http://www.equatornetwork.org/reporting-guidelines/care/ (accessed on Aug 19, 2016).

14. EQUATOR Network. http://www.equator-network.org/ (accessed on Aug 19, 2016).

15. Gastel B. Editing and proofreading your own work. AMWA J 2015; 30: 147-51. Available at http://www.authoraid.info/ en/resources/details/1272/ (accessed on Aug 18, 2016).

16. Gastel B. Oral and poster presentations: top tips. 2014. http://www.authoraid.info/en/resources/details/1187/ (accessed Aug 18, 2016).

17. Purrington C. Designing conference posters. http:// colinpurrington.com/tips/poster-design (accessed Aug 18, 2016).

18. Committee on Science, Engineering, and Public Policy, National Academy of Science, National Academy of Engineering, and Institute of Medicine of the National Academies. On Being a Scientist: A Guide to Responsible Conduct in Research. 3rd ed. Washington, DC: National Academies Press, 2009. http://www.nap.edu/catalog/ 12192/on-being-a-scientist-a-guide-to-responsible-conductin (accessed Aug 18, 2016).

19. IAP-InterAcademy Partnership. Doing Global Science: A Guide to Responsible Conduct in the Global Research Enterprise. Princeton and Oxford: Princeton University Press, 2016. http://www.interacademycouncil.net/24026/ 29429.aspx (accessed Aug 18, 2016).

20. Think. Check. Submit. http://thinkchecksubmit.org/ (accessed Aug 18, 2016).

B Gastel, Department of Integrative Biosciences and Department of Humanities in Medicine, Texas A\&M University, USA.

Correspondence: e-mail: bgastel@cvm.tamu.edu. 